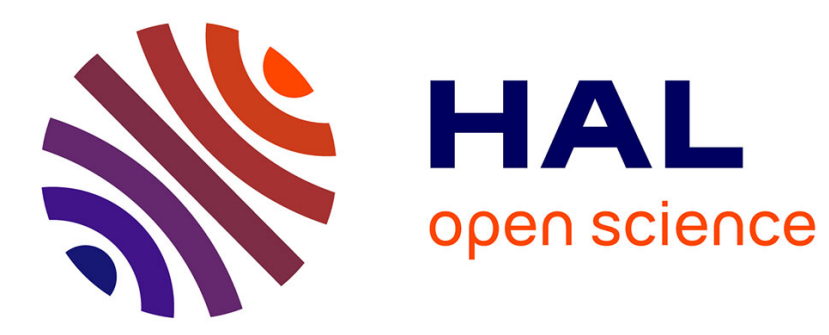

\title{
Interfacial interaction in PP/EPDM polymer blend studied by positron annihilation
}

\author{
Chen Wang, S. Wang, W. Zheng, Z. Qi
}

\section{To cite this version:}

Chen Wang, S. Wang, W. Zheng, Z. Qi. Interfacial interaction in PP/EPDM polymer blend studied by positron annihilation. Journal de Physique IV Proceedings, 1993, 03 (C4), pp.C4-261-C4-264. 10.1051/jp4:1993440 . jpa-00251483

\section{HAL Id: jpa-00251483 https://hal.science/jpa-00251483}

Submitted on 1 Jan 1993

HAL is a multi-disciplinary open access archive for the deposit and dissemination of scientific research documents, whether they are published or not. The documents may come from teaching and research institutions in France or abroad, or from public or private research centers.
L'archive ouverte pluridisciplinaire HAL, est destinée au dépôt et à la diffusion de documents scientifiques de niveau recherche, publiés ou non, émanant des établissements d'enseignement et de recherche français ou étrangers, des laboratoires publics ou privés. 


\title{
Interfacial interaction in PP/EPDM polymer blend studied by positron annihilation
}

\author{
C.L. WANG, S.J. WANG, W.G. ZHENG* ${ }^{*}$ and Z.N. QI* \\ Department of Physics, Wuhan University, Wuhan 430072, China \\ * Institute of Chemistry, Academia Sinica, Beijing 100080, China
}

\begin{abstract}
Positron lifetimes in polypropylene/ethylene-propylene-diene monomer blend (PP/EPDM, EPDM volume content $=40 \%$ ), pure PP and EPDM have been measured in the temperature range of 95-370K. We observed the $\gamma$ - and glass transitions in all samples and the transition temperatures $T_{\text {, }}$ and $T_{g}$ are determined. The blend has two lower $T_{g}$ s compared with pure EPDM and PP! At room temperature, the measured freevolume concentration in blend versus EPDM volume fraction is smaller than that calculated by the simple mixing. The different free-volume properties and $\mathrm{T}_{g} \mathrm{~s}$ between blend, PP and EPDM indicate the existence of interfacial interaction between PP and EPDM phases in blend.
\end{abstract}

\section{INTRODUCTION}

Polymer blends are of great importance in application because they have some different mechanical properties compared with that of conponents [1] e.g., PP/EPDM blend has a higher impact strength than pure PP, which depends on the content and size of EPDM particles [2]. The reason for this improvement is being investigated. A percolation model has been proposed to explain this improvement, where the enough interfacial interaction between two phases is assumed in the stress volume [1]. In order to understand the interfacial interaction in the blends, we performed the measurements of positron lifetime vs $\mathrm{T}$ and $\phi_{4}$.

\section{EXPERIMIENT}

Three kinds of samples, i.e. PP (melt index $=3 \mathrm{~g} / 10 \mathrm{~min}$, density $=0.905 \mathrm{~g} / \mathrm{cm}^{3}$ ), EPDM and PP/EPDM blends were prepared, where EPDM is a kind of uncrosslinked rubber with the Mooney viscosity of 45 and density of $0.870 \mathrm{~g} / \mathrm{cm}^{3}$. Blends were prepared by melt extrusion after mechanical mixing of PP and EPDM at 500K. Positron annihilation lifetime (PAL) was measured using a fast-fast coincident system with a time resolution of $270 \mathrm{ps}$. The raising temperature is controlled better than $0.5 \mathrm{~K}$. Half a million counts were collected for each spectrum. 


\section{RESSULIS AND DISCUSSTON}

Each spectrum was resolved into three components using the program PATFIT [3]. The longest-lived component $\tau_{3}$, has strong temperature dependence, is due to o-Ps annihilation in free-volume holes in amorphous regions, and its intensity $I_{\hat{j}}$ is sometimes considered to be proportional to hole concentration [4]. In the simple mixing of the filler EPDM and the matrix PP, i.e. there is no any interfacial interaction between two phases, the hole concentration and the fractional freevolume are conservable. If the transition rate of o- $\mathrm{P}_{\mathbb{S}}$ into the holes is the same for PP, EPDM and PP/EPDM [6], we have

$$
\begin{gathered}
I_{3 B}=I_{3 F} \cdot \Phi_{v}+I_{3 E} \cdot\left(1-\Phi_{v}\right) \\
R_{B}^{3} \cdot I_{3 B}=R_{F}^{3} \cdot I_{3 F} \cdot \Phi_{v}+R_{H F}^{3} \cdot I_{3 M}\left(1-\Phi_{v}\right)
\end{gathered}
$$

where $B, F$ and $M$ denote as the blend, filler BPDM and matrix PP, respectively, and $R$ is the average hole radius.

The temperature dependence of o-Ps lifetime shows the thermal expansion of free-volume holes. From the variations of $\tau_{3}$ and $I_{3}$ shown in Fig. 1 and 2 the $\gamma$ - and glass transition temperatures can be determined [5]. The detailed performance is presented in [6]. In Tab.1 the $T_{y}$ and $T_{g}$ measured by PAL and Dynamic Mechanical Analysis (DMA) are presented. The existence of two $T_{g}$ in blend shows the two phases in blend are immiscible.

\begin{tabular}{|c|c|c|c|c|}
\hline \multirow[b]{2}{*}{ Samples } & \multicolumn{2}{|c|}{$\mathrm{T}_{\mathrm{y}}(\mathrm{K})$} & \multicolumn{2}{|c|}{$\mathrm{T}_{\mathrm{E}}(\mathrm{K})$} \\
\hline & PAL & DMA & PAI & DMA \\
\hline EPDM & 160 & - & 220 & 239 \\
\hline $\mathrm{PP}$ & 165 & - & 280 & 286 \\
\hline PP/EPDM $(\phi=40 \%)$ & 160 & - & 205,270 & 223,280 \\
\hline
\end{tabular}

Tab. 1 The results of $T_{f}$ and $T_{g}$ measured by PAL and DMA.

The variations of $I_{3}$ in pure PP and EPDM vs $T$ are explained in $[5,6]$. Generally the increase in $I_{3}$ above $T_{g}$ suggests the creation of new free-volume holes, due to the onset of micro-Brownian motion of segments [5]. However, for PP/EPDM blend, it is evident that $I_{3}$ is nearly constant in the region of $T_{g 1} \leq T_{s} T_{g 2}$, which shows no new holes are created. It arises from the following reasons: 1). no new holes are 
created in the glassy PP; 2), although EPDM phase is rubbery when $T_{g 1} s T_{s} T_{g}$, the creation of new holes in EPD is strongly restricted by the interaction between EP and EPDM phases.

There are other evidences for existence of interfacial interaction in PP/EPDM. First, The $T_{g} s$ of the blend are shifted to a lower values from those of PP and EPDM, probably due to the formation of the emulsion interfaces with the excess free-volume [7]. In literature [8] the effects of several possible interfacial morphologies on the glass transitions are discussed. It is proposed that in an emulsified interface, there is small interfacial domains but no interfacial mixing, where the excess freevolume is developed. As result the mobility of macromolecules of both phases in the interface is increased, which may reduce the glass transitions temperature of the interface. A detailed calculation shows that the shift of $\mathrm{T}_{\mathrm{g}}$ is dependent on the concentration and the $T_{g}$ of interfacial layers [7].

Second, between 280K-340K, PP/EPDM has a silaller thermal expansion coefficient of fractional free-volume than $\mathrm{PP}$ and EPDM, which may result from the residual thermal stresses in the matrix and the filler due to the differences in coefficient of thermal expansion, Young's modules and Poisson's ratio between EPDM and PP [9]. From the temperature dependence of relative fractional free-volume $F_{f}=I_{3} \cdot V_{f}\left(V_{f}\right.$ is the measured free-volume by PAL), the thermal expansion coefficient of relative fractional free-volume, i.e., $\alpha_{\mathrm{p}}=\left(\mathcal{F}_{\mathrm{p}} / \partial \mathrm{J}\right)_{\mathrm{o}}$ can be evaluated [6]. For PP, EPDM and PP/EPDM, the values of $c_{\mathrm{p}}$ in the range of $280-340 \mathrm{~K}$ obtained by the linear fitting are $0.299,0.349$ and 0.290 , respectively. It is evident that PP/EPDM has the smallest value of $e_{\mathrm{r}}$ in the three samples.

Third, at room temperature, the measured $I_{3}$ and $R$ is smaller than the expected values obtained by eq. (1-2), as shown in Fig.3-4. This observation proves that the average packing density of segments in the bulk of PP/EPDM increases and the interaction between two phases is enhanced with the inorease in the EPDM content.

We have measured the curve of impact strength with the rubber EPDM volume fraction for PP/EPDM [2] and observed an onset increase of the impact strength at $\phi_{\mathrm{T}}=25 \%$, corresponding to a brittle-ductile transition [1]. Experimental studies show that the impact strength improvement of PP/EPDM blends is directly connected with the shear yield of PP matrix around EPDM particles [1,2]. The interfacial interaction is beneficial for the stress transfer between two phases and can restrict the glide of polymer chains at the interface, so the shear yield of matrix molecules will become more difficult under the impact force and the blends will have a higher impact strength. In this work, the measured free-volume properties suggest the existence of the interfacial interaction and the thermal tensile stress at the interface, which should be one of essential conditions for the improvement of mechanical properties of PP/EPDM [2]. The quantitative relation of free-volume and the mechanical properties in polymer blend is necessary for future study. 


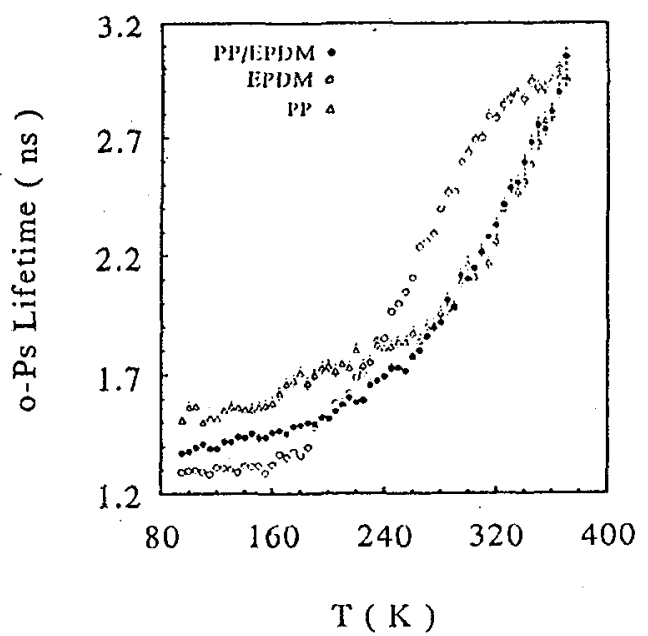

Fig. 1 the variation of o-Ps lifetime T/3 with $T$

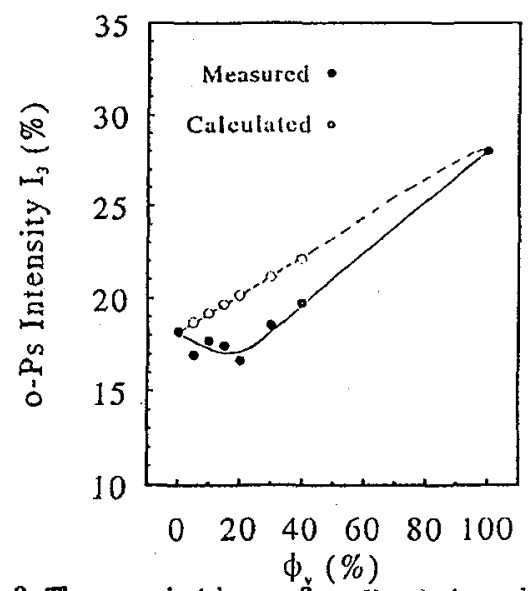

Fig. 3 The variation of o-Ps intensity $I_{3}$ with EPDM content

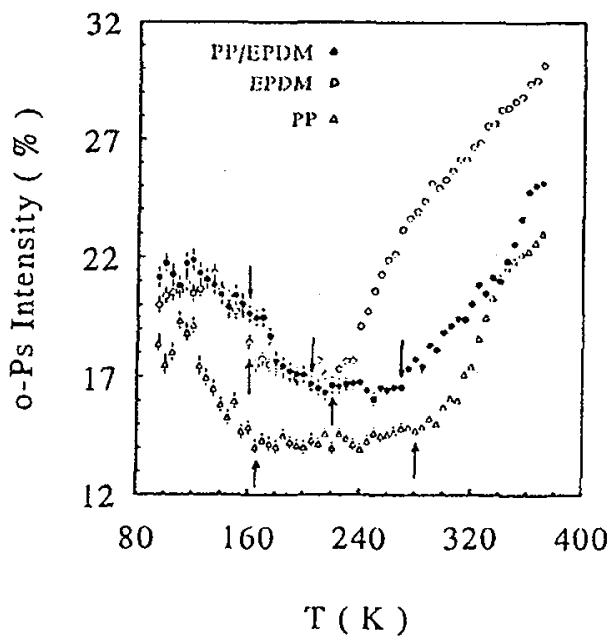

Fig. 2 The variation of $0-P s$ intensity $I_{3}$ with $\mathrm{T}$

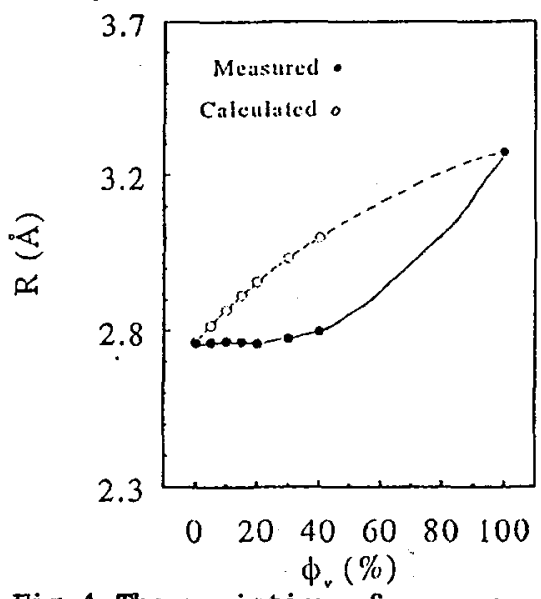

Fig. 4 The variation of average radius of free-volume hole with $\phi_{7}$

\section{REFERENCES}

[1] Wu, S, Polym. Inter. 29(1992)229

[2] Zheng, W.G, Li, Q and Qi Z.N, Chinese Sci.Bull. 37(1992) 904

[3] Kirkegaard, P, et al. Comput.Phys.Comnun. 23(1981) 307

[4] Jean, Y.C, et al. J.Polym.Sci.B, 24(1986) 1274

[5] Lin, D and Wang, S.J, J.Phys.C 4(1992) 3331

[6] Wang, C.L, Wang S.J, Zheng W.G and Qi Z.N, (to be published)

[7] Lipatov, Y.S, J.Appl.Polym.Sci. 22(1978) 1895; 25(1980) 1029

[8] Fried, J.R, in: Developments in Polymer Characterization, vol 4, Ed.

Dawkins, J.V, (Applied Science, London 1983)

[9] Low,I.M, J.Appl.Polym.Sci. 39(1990) 759 